\title{
Erratum to: Hebephilia as Mental Disorder? A Historical, Cross-Cultural, Sociological, Cross-Species, Non-Clinical Empirical, and Evolutionary Review
}

\author{
Bruce Rind • Richard Yuill
}

Published online: 25 September 2012

(c) Springer Science+Business Media, LLC 2012

Erratum to: Arch Sex Behav (2012) 41:797-829

DOI 10.1007/s10508-012-9982-y

There is a mistake, repeated three times, made by the publisher and typesetter at a late stage of production. The expression "DSM's 5-code" should be "DSM's V-code." This mistake occurred near the end of the Abstract (p. 797, bottom of left-hand column), in the section entitled "HD Approach" (p. 802, left-hand column near end of second paragraph), and in the section entitled "Concluding Remarks" (p. 824, righthand column near the middle of the paragraph). The V-code (but not the "5-code") is a section in the DSM, which contains non-disordered conditions that create significant problems in present-day society.

R. Yuill

Glasgow, Scotland, UK 